\title{
O QUE É MÉTODO CIENTÍFICO NA QUÍMICA DO COTIDIANO THE SCIENTIFIC METHOD IN DAY-TO-DAY CHEMISTRY
}

\author{
Marta Bellini ${ }^{1}$; Regina Maria Pavanello ${ }^{2}$ e José Marcos Batista ${ }^{3}$ \\ ${ }^{1}$ Profa. do Departamento de Fundamentos da Educação da Universidade Estadual de Maringá. \\ martabellini@uol.com.br \\ ${ }^{2}$ Profa da Pós-Graduação em Educação para a Ciência e Matemática da Universidade Estadual de \\ Maringá. reginapavanello@hotmail.com \\ 3 . Prof.de Química. Mestre em Educação para a Ciência e Matemática. Universidade Estadual de \\ Maringá.
}

\section{Resumo}

Neste artigo apresentamos a análise das argumentações que sustentam a noção de método científico na Coleção Química na abordagem do cotidiano, de Francisco Miragaia Peruzzo e Eduardo Leite do Canto, Editora Moderna. O objetivo foi verificar quais são as argumentações dos autores quando explicam aos professores e aos alunos a ciência química aplicada ao cotidiano. O critério para a escolha dessa Coleção foi a sua indicação pelo Programa Nacional do Livro Didático de Ensino Médio - PNLEM - de 2008 e sua proposta de ensinar/aprender a química pela abordagem do cotidiano. Nosso referencial teórico para o exame das argumentações foram os estudos de Breton, Lakoff e Jhonson, Perelman, Reboul e Chalmers. Os resultados indicam três problemas na abordagem do cotidiano realizada nessa Coleção: a) um, de dimensão epistemológica, que é a crença dos autores em que o conhecimento está fora do homem. Trata-se do postulado sustentado pela hipótese empirista de conhecimento: a de que se apreende apenas pela experiência, sem a necessidade da elaboração de hipóteses, de problemas de pesquisa, de metodologias diversas; b) um problema metodológico, decorrente do epistemológico, que é admitir apenas a OBSERVAÇÃO como instrumento para elaborar as teorias; c) e, por último, um problema pedagógico, decorrente dos anteriores, que é o de confundir o real do cotidiano do cientista (no seu laboratório pesando, medindo, fazendo experimentações, elaborando hipóteses) com as ilustrações dos livros didáticos e o real do cotidiano do aluno. Estes três níveis se entrelaçam e definem a metáfora OBSERVAÇÃO como condutora da produção da ciência, como fundamento de todos os métodos científicos e como exigência para o ensino e a aprendizagem.

Palavras-chave: ensino de química; livros didáticos de química; química do cotidiano

\begin{abstract}
The aim of this paper is to analyze the arguments foregrounding the scientific method for Chemistry teaching provided in the series Chemistry within the day-to-day approach, published by the Editora Moderna, Brazil and whose authors are Francisco Miragaia Peruzzo and Eduardo Leite do Canto. The article investigates the arguments used by the authors in their explanation to teachers and students of the Chemistry applied day-to-day issues. The choice of the mentioned series was based on its indication by the National Program for the High School Textbook in 2008 and its proposal to teach/learn Chemistry through daily experience. Analysis of arguments was based on the theoretical studies by Breton, Perelman, Reboul and Chalmers. Results show that the day-to-day approach of this Chemistry Series presents three problems: a) from a epistemological perspective, the authors deal with knowledge as being outside man, a postulate based on the empirical hypothesis of knowledge, or rather, that
\end{abstract}


learning comes through experience. So, there is no need for hypotheses, research and different methodologies; b) the epistemological issue brings forth a methodological problem, namely, that observation is the sole tool for the elaboration of theories; c) the epistemological and methodological issues give rise to a pedagogical problem: the nondistinction between the reality of scientists' day-to-day experience (working in the laboratory, weighing, measuring, experimenting and elaborating hypotheses) and the students' reality of their daily experience achieved through textbooks illustrations. The above levels overlap and define the metaphor Observation as conductive of producing science, or rather, as the foundation of all scientific methods and an exigency for teaching and learning.

Keywords: Chemistry teaching; high school Chemistry textbooks; day-to-day Chemistry

\section{Introdução}

Neste texto examinamos as argumentações e as ilustrações do livro Química na abordagem do cotidiano, de Francisco Miragaia Peruzzo e Eduardo Leite do Canto, e apresentamos como os autores definem a ciência química e o método científico em sua apresentação de uma abordagem da química no cotidiano.

O objetivo do trabalho aqui exposto foi compreender a vinculação entre os conteúdos da química e as propostas de aulas experimentais. Esta Coleção da Editora Moderna é composta de três volumes, um para cada série do Ensino Médio. Os critérios adotados para a escolha dessa Coleção foi a sua indicação pelo Programa Nacional do Livro Didático de Ensino Médio - PNLEM - de 2008 e sua proposta de ensinar/aprender a química pela abordagem do cotidiano.

Os problemas de pesquisa e as hipóteses que nortearam este trabalho foram delimitados pelos estudos de retórica conduzidos por Breton (2003), Lakoff e Jhonson (2002), Reboul (2004) e Perelman (2005). Os problemas de investigação ficaram assim definidos: Como os autores da Coleção Química, ao partirem da abordagem do cotidiano, apresentam e concebem as situações experimentais em química? De que forma os autores estabelecem a noção de método científico quando trazem a abordagem do cotidiano para a aprendizagem em química?

Nossa hipótese, corroborando o estudo de Moreira e Osterman (1993), é a de que as atividades experimentais propostas na maioria dos livros didáticos de biologia, física e química - e em especial as da coleção que examinamos para a realização deste trabalho - pensam as atividades experimentais como método científico. 
Chalmers (1993, p.17) diz que nos tempos modernos a ciência é altamente considerada. Ao termo científico, afirma o autor, atribuímos uma linha de pesquisa, uma linha de raciocínio ou um tipo de confiabilidade. Dado este atributo especial, Chalmers (1993, p. 17) pergunta, "Mas o que é tão especial em relação à ciência? O que é 'método científico' que comprovadamente leva a resultados especialmente meritórios ou confiáveis?" Chalmers (1993) nos remete a pensar método científico como decorrente de fundamentos epistemológicos e metodológicos. Para Chalmers não há uma única definição de método científico. De acordo com as correntes teóricas e metodológicas de pesquisa têm-se diferentes explicações, das quais a mais antiga e mais arraigada entre os pesquisadores é o indutivismo. Para esta concepção, método científico é aquele que afirma - com base no raciocínio indutivista - que a ciência é resultado de "uma lista finita de proposições singulares de observação" retiradas das experimentações e não de bases puramente lógicas. Ciência, nessa visão, é uma coleção de dados (CHALMERS, 1993).

A ciência é compreendida como produto da prática experimental quando o pesquisador pensa os dados como a forma ideal para se chegar a uma teoria. Nesse caso, as ciências surgem da prática experimental sem necessidade de teorias que façam o papel de hipóteses ou colaborem para a elaboração de novos problemas, metodologias e técnicas. Nesse percurso, torna-se natural chegar-se à idéia de que o conhecimento científico é estático (MOREIRA; OSTERMAN, 1993).

\section{Procedimentos Metodológicos}

Nossa investigação pautou-se em uma abordagem qualitativa para efetivar o estudo de aspectos da comunicação presentes em discursos de diversos tipos. Trata do estudo que compreende a Retórica (BAUER; GASKELL, 2002).

Para Bauer e Gaskell (2002) é possível analisar os argumentos de documentos a partir de unidades da linguagem - frases, palavras - de acordo com o objetivo da pesquisa. Com essa intenção analisamos como os autores argumentam sobre a necessidade de abordar a química no cotidiano do aluno e como sustentam o conceito de método científico para o ensino dessa ciência.

Os livros analisados foram os três volumes da Coleção Química na abordagem do cotidiano, de Francisco Miragaia Peruzzo e Eduardo Leite do Canto, que tratam da química geral e inorgânica. A coleção, publicada pela Editora Moderna, consta no catálogo do Programa Nacional do Livro para o Ensino Médio, do Ministério da 
Educação, de 2007e foi indicada pelo PNLEM de 2008. A edição utilizada foi a de 2003, com selo de recomendação do PNLEM para 2008.

Para o exame das unidades de linguagem tomamos, depois de cada capítulo, a seção intitulada Destaque, na qual os autores relacionam os conteúdos de química com atividades experimentais cotidianas, as definições de método científico e de ciência.

No volume 1 da Coleção analisada temos a definição de ciência, de método científico. Para tanto, os autores recorrem à definição de mapa conceitual como estratégia de ensino de química. Mapas conceituais são definidos, pelos autores, como "diagramas que inter-relacionam conteúdos conceituais". De acordo com os autores, tanto os professores como os alunos podem elaborar mapas conceituais; isso permitirá "exercitar o entendimento dos conceitos, como também a maneira como uns se relacionam com os outros" (PERUZZO; CANTO, 2003, p. III). Neste primeiro volume e nos demais os autores ressaltam as observações que devemos fazer aos alunos sobre a química e o dia a dia mostrando um conjunto extenso de exemplos e imagens.

O primeiro volume consta de 15 capítulos (com 344 páginas mais 80 páginas do Manual do Professor), apêndices, as respostas aos exercícios, a lista de siglas e bibliografia. No segundo volume temos 11 capítulos (com 344 páginas e mais 88 páginas do Manual do Professor); uma seção intitulada Tópico avançado "Conceitos ácido-base de Bronsted-Lowry”, apêndices, respostas dos exercícios de cada capítulo, lista de siglas e bibliografia. O terceiro volume é composto de 11 capítulos (com 264 páginas e mais 64 páginas do Manual do Professor) apêndices, respostas dos exercícios de cada capitulo, lista de siglas e bibliografia.

\section{As etapas da pesquisa}

As etapas de nossa pesquisa foram:

1. Exame das sessões intituladas Destaque tomando como exemplo algumas ilustrações presentes nos três volumes.

2. Análise das noções de método científico, atividade experimental, experimentação.

3. Apontamentos dos níveis epistemológicos, metodológicos e pedagógicos presentes na concepção de método científico dos autores.

\section{Subsídios teóricos para a análise retórica}


Um "elemento essencial da atividade científica é 'comunicar', e isso implica persuadir os ouvintes que algumas coisas são importantes e outras não" (BAUER; GASKELL, 2002, p. 28). É a comunicação que fundamenta toda construção do conhecimento científico produzido pela humanidade e é por meio dela que "[...] o conhecimento científico transforma a verossimilhança de nossas opiniões em uma ilusão de verdade" (BRETON, 2003, p. 44). Além dessa dimensão, é importante observar ser passagem da linguagem científica para a linguagem escolar que ocorre outra transformação. Da retórica ou comunicação do conhecimento científico elaborada pelos cientistas ao conhecimento científico escolar - realizado pelos autores de livros didáticos, professores - há um percurso que foi definido como retórica forçada (CONTENÇAS, 1999). Isto é, no processo de transmissão dos conhecimentos das ciências, os conceitos, as definições e a própria comunicação desses conhecimentos aparecem em uma nova linguagem visando, na maioria das vezes, mais entusiasmar do que argumentar com os alunos (CONTENÇAS, 1999).

Argumentar é comunicar; esta situação implica em oradores (ethos), auditório (pathos) e os argumentos (logos), ou seja, em três dimensões da comunicação. Argumentar não é convencer a qualquer preço; não se convence pela sedução, violência ou manipulação; [...] "argumentar é raciocinar, propor uma opinião aos outros dandolhes boas razões para aderir a ela" (BRETON, 2003, p. 26).

Não basta saber falar; é preciso argumentar, mas também conhecer o discurso do outro, adaptar-se à platéia. Breton (2003, p.23) chama de contexto da recepção o conjunto de valores e opiniões do auditório que o orador precisa conhecer para favorecer a partilha de suas idéias com as idéias dos outros. É isso que permite a aceitação ou a recusa do argumento do orador.

Para construir um discurso, segundo Reboul (2004), é preciso que o orador faça quatro movimentos: a) a invenção ou (heurésis) que diz respeito aos meios de que o orador dispõe para falar ou escrever; b) a disposição (táxis) é o plano ou ordenação dos argumentos; c) a elocução (lexis) é o estilo do discurso ou da sua escrita; e d) a ação (hypocrisis) que é o ato em si de proferir o discurso, implicando os efeitos de voz, de mímica e de gestos (REBOUL, 2004, p. 43).

Como recurso argumentativo o orador recorre à linguagem ou escrita construindo-as com as diferentes figuras de retórica. Dentre estas figuras a metáfora destaca-se pela capacidade de tecer analogias. A analogia e a metáfora constituem 
argumentos de presença e aumentam a intensidade da adesão do auditório às idéias do orador.

As figuras de retórica classificam-se conforme a sua relação com o discurso, a saber: a) figuras de palavras: que dizem respeito à matéria sonora do discurso, como a rima; b) as figuras de sentido: referem-se a significação das palavras como a metáfora; c) as figuras de construção que referem-se à estrutura da frase, ou do discurso, como a elipse; e d) figuras de pensamento que se referem ao discurso com seu sujeito (orador) com ou sem seu objeto.

Na situação de ensino a comunicação é permeada pela figuras de retórica que conduzem ou não à situação de negociação de significados. Assim, a negociação de significados se configura como a troca de argumentos em um processo que leva ou não à compreensão daquilo que está sendo ensinado.

\section{Resultados: a análise da Coleção Química na abordagem do cotidiano}

Os três volumes de a Química na abordagem do cotidiano apresentam capas com ilustrações que procuram despertar a atenção dos estudantes para elementos da natureza "relacionados" com a química. No volume 1, temos as rochas, no segundo, os artefatos de metais e, no terceiro, as frutas. Os volumes apresentam ilustrações que nos remetem ao cotidiano.

Nos três volumes, na abertura que explica a estrutura dos livros, há um item Motivação no qual está exposto um dos principais argumentos que perpassa todas as seções posteriores, especialmente, a seção Destaque de cada capitulo. Escrevem os autores $(2003$, p. II):

Observar é um dos procedimentos fundamentais para a Ciência e também para qualquer cidadão, pois é importante modo de obter informações para, posteriormente, processá-las, compreendê-las e sistematizá-las.

Na página 9, do volume 1, os autores estabelecem o que é MÉTODO CIENTÍFICO:

Antes mesmo de 2.500 a.C., povos da Antiguidade (egípcio, babilônios e chineses) já haviam percebido que o movimento dos astros e das estrelas apresenta uma REGULARIDADE, ou seja, repete-se de tempos em tempos. Por volta de 1000 a.C. os caldeus, OBSERVANDO essas REGULARIDADES, foram capazes de prever com razoável precisão o acontecimento de futuros eclipses. 
Esses fatos ilustram bem a preocupação básica das Ciências Naturais: observar as regularidades nos acontecimentos, conhecidas como "leis da natureza”, e, por meio delas, adquirir capacidade de fazer previsões.

A moderna pesquisa em Química segue por esse mesmo caminho. Um cientista decidido a atuar em certo ramo da Química precisa, antes de mais nada, estudar o que já se descobriu a respeito desse assunto escolhido. A partir daí, deve decidir qual será o problema a investigar e elaborar experiências de laboratório, que lhe permitirão executar OBSERVAÇÕES EXPERIMENTAIS. Essas observações podem ser de dois tipos:

* qualitativas: aquelas em que não envolvem dados numéricos;

* quantitativas: as que provêm de medidas, com a utilização de aparelhos, e constituem-se de dados numéricos.

Após a execução das experiências, podem-se observar as regularidades e, a partir delas, enunciar um "princípio" ou uma lei, ou seja, uma frase ou equação matemática que expresse a regularidade observada.

A seguir, pode-se apresentar uma teoria, ou seja, uma proposta de explicação para os fatos experimentais e as leis. Uma teoria é considerada satisfatória quando, ao ser testada em novas situações, obtém sucesso. Quando tal sucesso não é conseguido, ela deve ser modificada ou, dependendo do caso, abandonada e substituída. er modificada ou, dependendo do caso, abandonada e substuta de explicaç "como "prever com razoa, repete-se de tempos em tempos.

As ciências naturais, como se referem os autores à física, à biologia e à química, são produtos da observação humana. Nesse percurso, na página 24, Seção Destaque do capitulo 1 - As soluções e o cotidiano - a imagem de uma garrafa mineral é apresentada como exemplo de solução aquosa com vários solutos presentes. VER ou OBSERVAR a imagem, para os autores, consiste em MÉTODO CIENTÍFICO. É importante ressaltar que os autores tomam OBSERVAÇÃO como um dos passos do método de investigação do percurso indutivista de um fenômeno natural e como OBSERVAÇÃO da ilustração. Realidade de pesquisa (de fenômenos naturais dos quais se quer apreender o significado) e desenho de um objeto não têm sinal de igualdade. Observar o desenho de uma garrafa de água mineral e a descrição de sua composição não se traduz em método científico. 


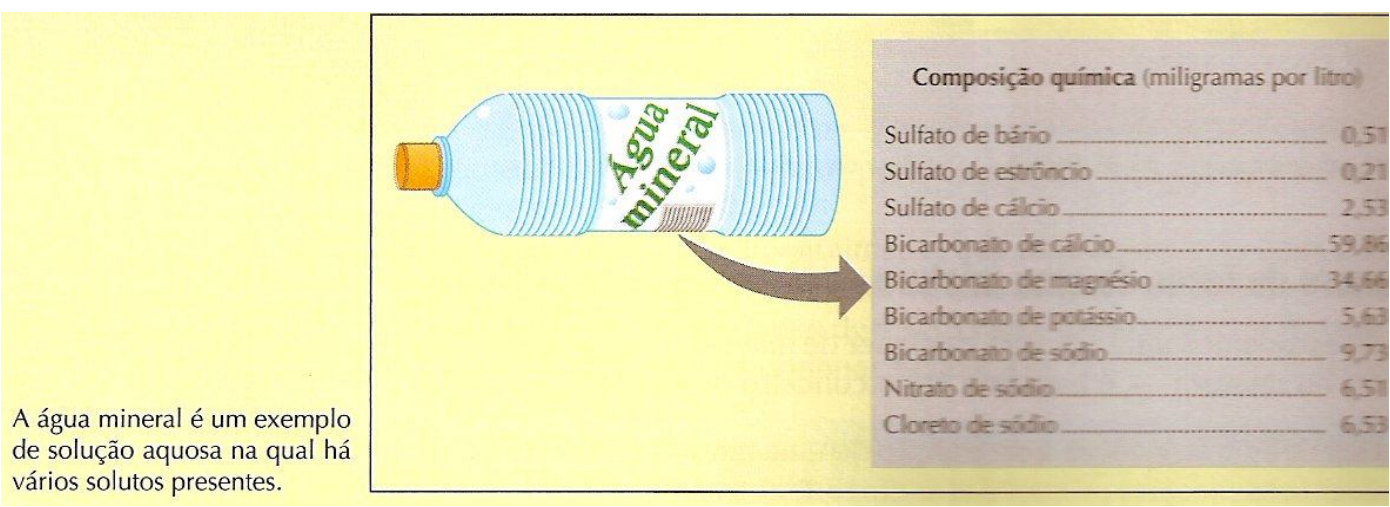

Figura 1: o desenho de uma embalagem de água mineral

$\mathrm{Na}$ ilustração da página 42 (segunda figura) do volume 1, aparece a mesma concepção na apresentação de duas palhas de aço, uma seca e outra molhada. Os autores solicitam aos leitores que esperem um tempo e depois observem o que ocorre com o material. O objetivo é que os alunos saibam explicar como ocorre a ferrugem, nesse caso, pelo contato com a água e oxigênio.

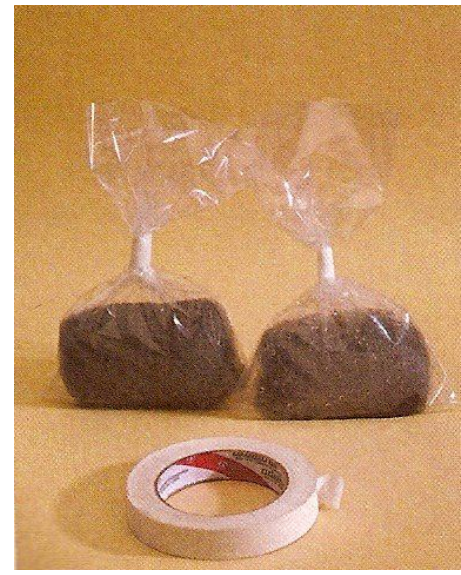

Figura 2: as embalagens de duas palhas de aço e uma fita "crepe".

Para ampliar a compreensão do fenômeno da ferrugem, os autores também propõem a observação da seguinte imagem (figura três) na página 176 do volume 1 . A ilustração sugere o que vemos em nosso cotidiano. Os autores querem mostrar o resultado da reação entre o ferro e o oxigênio, a ferrugem. No entanto, o que observamos nessa imagem 3 são parafusos enferrujados (dada a cor dos objetos). Os alunos não vêem a reação química, vêem uma imagem de parafusos. Mais uma vez os autores, conduzidos pela metáfora OBSERVAÇÃO, confundem ver uma ilustração e conhecer uma reação química entre ferro e ar. 


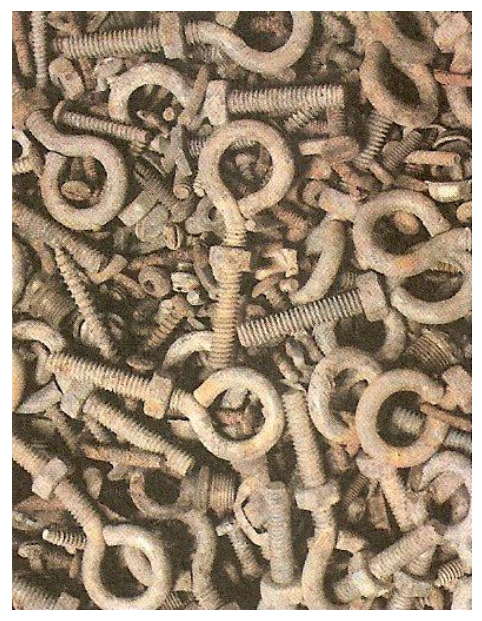

Figura 3: parafusos de parede de ferro

Na página 44, do volume 1 , os autores solicitam que os alunos e professores observem a imagem de um pedaço de fígado em contato com a água oxigenada. Pretendem, com a observação, que os alunos explorem o fenômeno e explicitem a reação. Vemos, na ilustração, no local em que foi pingada a água oxigenada, bolhas na superfície do pedaço de fígado. Compreender esse fenômeno é necessário também, entender que as células do fígado contêm oxigênio (presente no sangue) e que a água oxigenada reage com esse oxigênio. Dessa reação, o $\mathrm{O}_{2}$ é liberado formando a espuma que vemos na ilustração. O fígado apresenta uma enzima, a catalase, que tem características oxiredutoras, ou seja, decompõe a água oxigenada em água e oxigênio. Todavia, somente observar a ilustração não garante aos alunos a compreensão do fenômeno, mesmo sendo este um fenômeno cotidiano.

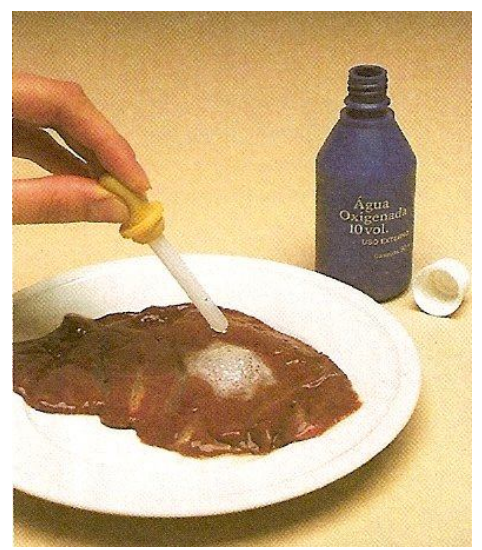

Figura 4: ilustração do pedaço de fígado com água oxigenada. 
Na página 127, do volume 1, é apresentada a ilustração do que os autores chamam de queratina. Mas, o que observamos nessa imagem? Vemos cabelos, ou como dizem os autores, cabelos com queratina. Na verdade, vemos uma imagem de uma moça com cabelos claros; não vemos queratina. Mais uma vez, a ilustração parece falar por si mesma; é só observar e veremos a queratina.

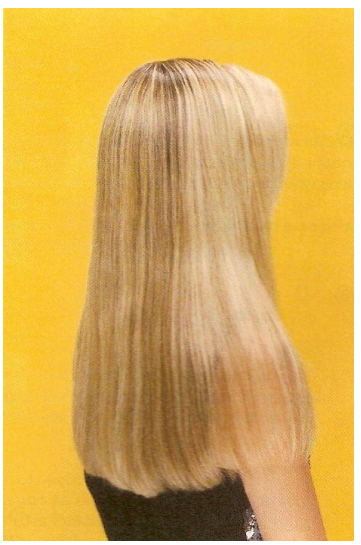

Figura 5: ilustração de queratina para os autores.

Para estudo da poluição, na página 15 do volume 2, a imagem da vida urbana de uma cidade grande quer garantir a compreensão dos gases que poluem o ar.

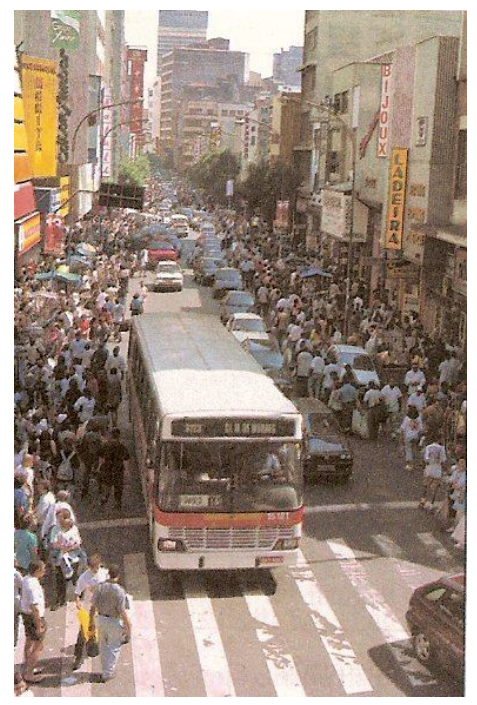

Figura 6: poluição em uma cidade grande.

No capitulo 3, página 40, os autores propõem a observação de diferentes grupos de pimentas, plantas que vemos no dia a dia, como forma de observar e fazer analogia 
com os grupos de substâncias químicas. Dois problemas aparecem para o entendimento do aluno: os agrupamentos de plantas podem ser vistos ou observados pelo aluno, mas para a compreensão de como surgem os grupos, este deve reconhecer diferenças biológicas e anatômicas. Em segundo lugar, observar plantas, visíveis a olho nu, e observar agrupamentos de substâncias químicas exige dos alunos uma fundamentação teórica e experimentações em pequena escala. Como visualizar moléculas, átomos?

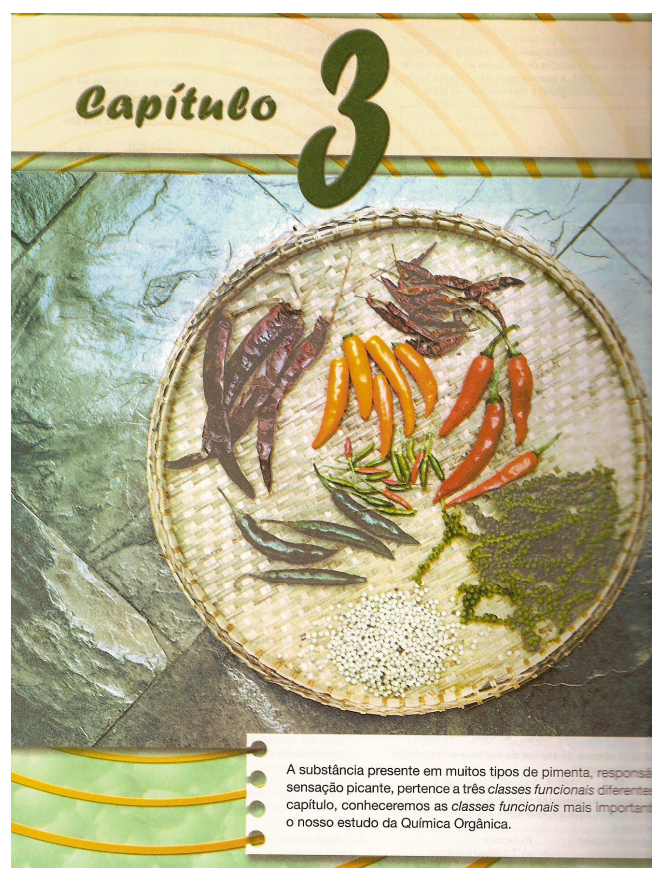

Figura 7: pimentas de diferentes grupos para compreender as classes funcionais do estudo de Química Orgânica.

No volume 3, página IV, temos a mesma situação pedagógica e "científica": observar o tomate; para os autores, é observar e apreender como esse vegetal é constituído. Mas, como apreender a constituição das moléculas, dos átomos, do modelo de reações desse vegetal como alimento humano? 


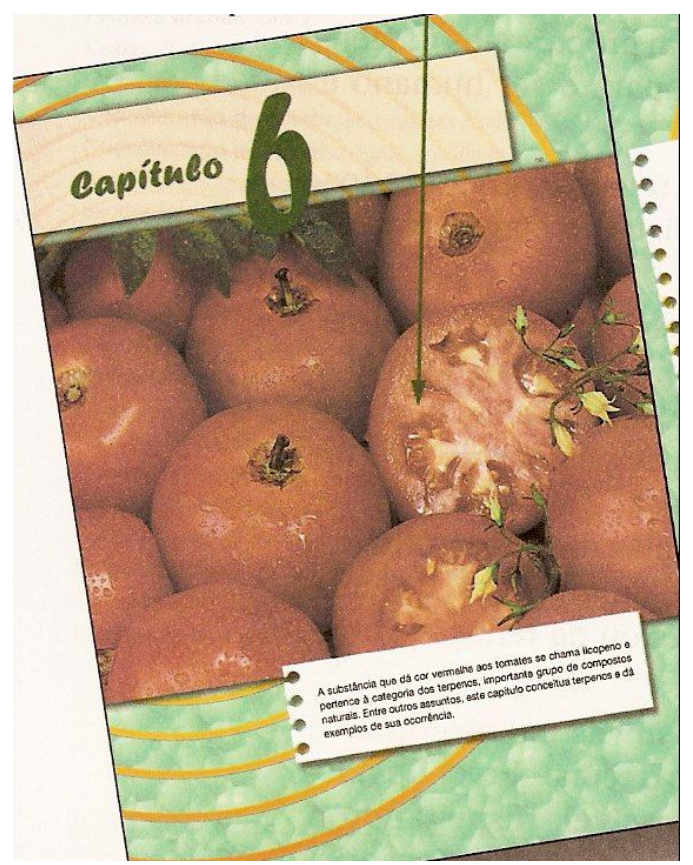

Figura 8: tomates representando as substâncias que contêm.

\section{Conclusão}

Os argumentos acerca do método científico nos três volumes da Coleção Química na abordagem do cotidiano, da Editora Moderna, de autoria de Francisco Miragaia Peruzzo e Eduardo Leite do Canto e que abordam a química geral e a inorgânica, indicam:

a) uma noção de método científico fundamentada na OBSERVAÇÃO de situações supostamente do cotidiano do aluno. O observador/aluno precisa observar as REGULARIDADES A NATUREZA que, por sua vez, são ENUNCIADAS COMO LEIS OU PRINCÍPIOS com que explicamos uma TEORIA que é ACEITA, SUBSTITUIIDA ou APRIMORADA. O observador é um agente passivo da natureza e da ciência, pois, para os autores, o que se descobre é a regularidade da natureza. Trata-se de uma concepção empirista. A regularidade não é uma criação do pesquisador/cientista; ela existe antes, é preciso descobrila, ela vem de fora para a cabeça do pesquisador. Para sua descoberta é necessário OBSERVAR. É a observação que leva o aluno a entender a química no cotidiano. Mas, como observar átomos? Como observar moléculas? Mas, como relacionar, mediante a observação de um elemento real da natureza, a sua 
composição química e as possíveis reações que são desencadeadas? Nas diversas situações experimentais os autores solicitam ao aluno a observação do resultado de uma reação química para sua compreensão. Este tipo de procedimento aumenta ainda mais a distância entre a teoria, que explica o fenômeno real, e a observação, o que impede a aprendizagem significativa dos conceitos químicos, físicos e matemáticos.

b) Os autores propõem o esquema OBSERVAÇÃO - REGULARIDADE ENUNCIADOS - LEIS - TEORIA (aceitas ou não) como a relação lógica entre os conceitos, ou seja, seu mapa conceitual. O mapa conceitual, nessa ótica, não é uma estratégia de aprendizagem, mas uma decorrência do método científico. Os autores, mais uma vez, se enganam. Tomam um procedimento de ensino como um procedimento científico. Mapas conceituais são modelos de aprendizagem propostos para se compreender e explicar como ocorre a construção de conhecimentos cognitivos. Não são parte de métodos científicos.

c) Para os autores existem observações experimentais qualitativas e quantitativas; as observações qualitativas "não envolvem dados numéricos", e as quantitativas são "as que provêm de medidas, utilização de aparelhos e se constituem de dados numéricos" (PERUZZO; CANTO, 2003, p. 9). As observações experimentais "servem para observar as regularidades da natureza, e a partir delas, enunciar um "principio" ou uma lei, ou seja, uma frase ou equação matemática que expresse a regularidade observada" (PERUZZO; CANTO, 2003, p. 9). Pode-se concluir que, para os autores, experimentação é observação. Uma metáfora difícil de aceitar para a ciência química, a qual tem como objeto de estudo experimentações elementos quase sempre não visíveis a olho nu. Como observar átomos, reações, cadeias químicas em uma experimentação? Podemos também afirmar que método, para os autores, baseia-se na concepção de que há regularidade da natureza e os cientistas a desvendariam em forma de conhecimento. Há algo fora da cabeça dos cientistas e estes a formulariam para nós por meio da observação.

Nas seções DESTAQUE dos três volumes, os autores referem-se aos procedimentos metodológicos de uma investigação como OBSERVAÇÃO de processos da vida 
cotidiana como, por exemplo, observar IMAGENS do que é uma solução de água mineral, cabelos e parafusos no processo de ferrugem. Mas, são as imagens cotidianas, atividades "experimentais"? Claro que não. As imagens, as ilustrações são recursos didáticos para trazer ao aluno alguma proposta de atividade ou de pensamento. As imagens não são a realidade, são a sua representação.

Cabe-nos assinalar três problemas centrais na Coleção Química na abordagem do cotidiano:

1) Um, de nível epistemológico, que se constitui na presença nos textos/argumentos dos autores da crença de que o conhecimento está fora do homem, algo estanque e acabado que pertence à natureza. Somos apenas receptáculo dos conhecimentos; estes são impressos em nosso cérebro quando descobrimos, ou aprendemos a regularidade da natureza. É uma posição sustentada pela hipótese empirista de conhecimento: a de que se apreende pela experiência. Não há necessidade de elaboração de hipóteses, de problemas de pesquisa, de metodologias diversas.

2) Um, de nível metodológico, decorrente do epistemológico, que é admitir apenas a OBSERVAÇÃO como dimensão científica e a mediante ela compreender a teoria. Embora a química seja uma ciência experimental, ela não pode prescindir da OBSERVAÇÃO PENSADA, ou seja, orientada por teorias, hipóteses. Nesse caso, os autores atuam, nos reportando a Chalmers (1993), como empiristas ingênuos, cuja crença os leva a apresentar a ciência como uma coleção de dados. E ainda temos que supor que o caminho para o conhecimento seja igual para todos os estudantes e todas as situações. Nesse sentido, a aprendizagem ocorre dependendo apenas do esforço dos alunos.

3) Outro, no nível pedagógico, decorrente do epistemológico e metodológico, que é o de confundir o real do cotidiano do cientista (em seu laboratório pesando, medindo, fazendo experimentações, elaborando hipóteses, leis, teorias) com as ilustrações dos livros didáticos e o real do cotidiano do aluno. Os autores cometem um erro pedagógico e epistemológico quando solicitam aos usuários 
dos livros didáticos construir a idéia de método científico (teoria, experimentação, observação pensada pela teoria) pela observação de desenhos, fotografias e esquemas.

Estes três níveis se entrelaçam e mostram, nessa coleção, a metáfora OBSERVAÇÃO como condutora da produção da ciência, como fundamento de todos os métodos científicos e como exigência para o ensino e a aprendizagem.

Esta abordagem traz dois problemas. O primeiro relacionado à aprendizagem do aluno, uma vez que o induz à ideia de que os conhecimentos de química podem ser observados no seu cotidiano ou que estamos adotando o método científico ao observarmos a fervura da água, por exemplo. O segundo, relacionado à conduta epistemológica e didática do professor de química que, ao adotar o livro didático e sua noção de química do cotidiano, reforça o sentido comum de conhecimento que temos de química. O ensino de química, nesse caso, ocorre pela noção de que o fenômeno que vejo é o modelo, a realidade é extensão do pensamento. Uma concepção empirista que ignora pensamento e realidade como dimensões distintas.

Salientamos que os procedimentos de observação, apresentados na obras analisada, não esclarecem como deverá ocorrer a aquisição dos conhecimentos científicos decorrentes. Conseqüentemente, podemos questionar que tipos de relações os alunos poderão fazer entre a observação das imagens e o saber científico. Em geral, temos observado que o aluno acaba por desvincular a teoria que aprende na escola das diversas situações reais do seu dia a dia em que esses conhecimentos podem ser aplicados.

A idéia de inserção, nos livros didáticos de química, de diversas imagens que remetem ao cotidiano do aluno nos parece ter exatamente essa intenção de estreitar as relações entre a teoria e a realidade que é, inclusive, uma das orientações dadas pelos PCNs e pelas Diretrizes Curriculares. No entanto, a observação de imagens relacionadas com o conteúdo pode conduzir o aluno a outra realidade que não é a do conhecimento científico e também não é aquela que ele vivencia. As imagens extraídas e apresentadas neste artigo confundem-se ao sentido comum que damos, no dia a dia, à química.

Finalmente, vale destacar a grande importância que a imagem apresenta no processo de ensino e aprendizagem, em relação ao texto escrito e ao discurso do professor. Segundo Bruzzo (2004, p. 1360): 
As imagens podem ser compreendidas como uma forma de deleite, mera distração para o leitor, como maneira de reiteração do texto escrito, ou seu substituto, na forma de resumo em esquema ilustrado e, não raro, com a função retórica de afirmação do saber científico.

Nesse sentido, a utilização de imagens nos livros didáticos de química para ilustrar o que é o método de observação científica deve ser analisada do ponto de vista epistemológico posto que: a) as ilustrações não são a realidade, são as representações do que observamos e pensamos acerca de um fenômeno ou experimento, ou seja, o desenho do fenômeno não é o fenômeno; b) o que observamos em um experimento laboratorial na área de química não são os modelos, observamos as etapas do método e como as realizamos com instrumentos específicos, os resultados sendo sempre a interpretação ou as representações que fazemos mediante os resultados obtidos.

\section{Livro didático analisado:}

PERUZZO, Francisco Miragaia; CANTO, Eduardo Leite do. Química na abordagem do cotidiano. São Paulo: Editora Moderna, 2008.

\section{Referências}

BAUER, Martin W.; GASKELL, M. Pesquisa qualitativa com texto, imagem e som. Trad. Pedrinho A. Guareschi. Petrópolis, RJ: Vozes, 2002

BRETON, Philippe. A argumentação na comunicação. Trad. Viviane ribeiro. 2. ed. Bauru, SP: EDUSC, 2003.

BRUZZO, Cristina. Biologia: Educação e imagens. EDUC. SOC. v. 25, n. 89: p, 13591378, set./dez. de 2004.

CONTENÇAS, Paula. A Eficácia da Metáfora na Produção da Ciência: o caso da genética. Coleção: Epistemologia e sociedade. Lisboa: Instituto Piaget, 1999.1993)

CHALMERS, A. F. O que é ciência afinal? Tradução de Raul Filker. São Paulo: Editora Brasiliense, 1993.

LAKOFF, George; JOHNSON, Mark. Metáforas da Vida Cotidiana. Campinas: Mercado de Letras, 2002.

LOPES, Alice Ribeiro Casimiro. Currículo, conhecimento e cultura: construindo tessituras plurais. In: CHASSOT, Attico; OLIVEIRA, Renato José de. (Org). São Leopoldo:Ed. Unisinos, 1998.

OSTERMANN, Fernanda; MOREIRA, Marco Antonio. Sobre o Ensino do Método Científico. CADERNIO CATARINENSE de ENSINO DE FISICA. v. 10, n. 2: p, 108117, agosto de 1993.

PERELMAN, Chaim. Tratado da argumentação: a nova retórica. Trad. Maria Emantina de Almeida Prado Galvão. 2. ed. São Paulo: Martins Fontes, 2005.

REBOUL, Olivier. Introdução à Retórica. Tradução de Ivone Castilho Benedetti. 2. ed. São Paulo: Martins Fontes, 2004. 241 p. 